\title{
Science for Society Workshop Summary Report
}

\author{
February 2012
}

Prepared by

Amy K. Wolfe, David J. Bjornstad, W. Christopher Lenhardt, Barry L. Shumpert, and Stephanie A. Wang

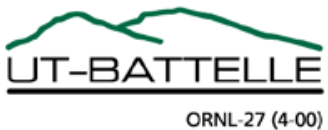




\section{DOCUMENT AVAILABILITY}

Reports produced after January 1, 1996, are generally available free via the U.S. Department of Energy (DOE) Information Bridge.

Web site http://www.osti.gov/bridge

Reports produced before January 1, 1996, may be purchased by members of the public from the following source.

National Technical Information Service

5285 Port Royal Road

Springfield, VA 22161

Telephone 703-605-6000 (1-800-553-6847)

TDD 703-487-4639

Fax 703-605-6900

E-mail info@ntis.gov

Web site http://www.ntis.gov/support/ordernowabout.htm

Reports are available to DOE employees, DOE contractors, Energy Technology Data Exchange (ETDE) representatives, and International Nuclear Information System (INIS) representatives from the following source.

Office of Scientific and Technical Information

P.O. Box 62

Oak Ridge, TN 37831

Telephone 865-576-8401

Fax 865-576-5728

E-mail reports@osti.gov

Web site http://www.osti.gov/contact.html

This report was prepared as an account of work sponsored by an agency of the United States Government. Neither the United States Government nor any agency thereof, nor any of their employees, makes any warranty, express or implied, or assumes any legal liability or responsibility for the accuracy, completeness, or usefulness of any information, apparatus, product, or process disclosed, or represents that its use would not infringe privately owned rights. Reference herein to any specific commercial product, process, or service by trade name, trademark, manufacturer, or otherwise, does not necessarily constitute or imply its endorsement, recommendation, or favoring by the United States Government or any agency thereof. The views and opinions of authors expressed herein do not necessarily state or reflect those of the United States Government or any agency thereof. 
Environmental Sciences Division

\title{
SCIENCE FOR SOCIETY WORKSHOP SUMMARY REPORT ${ }^{\dagger}$
}

\author{
A. K. Wolfe \\ D. J. Bjornstad \\ W. C. Lenhardt \\ B. L. Shumpert \\ S. A. Wang
}

Date Published: February 2012

Prepared by

OAK RIDGE NATIONAL LABORATORY

Oak Ridge, Tennessee 37831-6283

managed by

UT-BATTELLE, LLC

for the

U.S. DEPARTMENT OF ENERGY

under contract DE-AC05-00OR22725

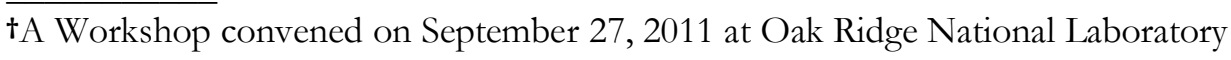





\section{CONTENTS}

SCIENCE FOR SOCIETY WORKSHOP — EXECUTIVE SUMMARY …......................... 1

SCIENCE FOR SOCIETY WORKSHOP — OVERVIEW …...............................................

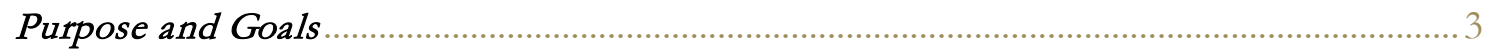

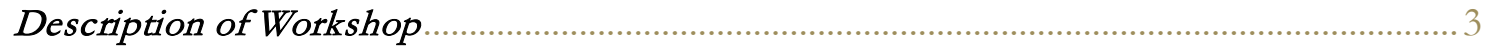

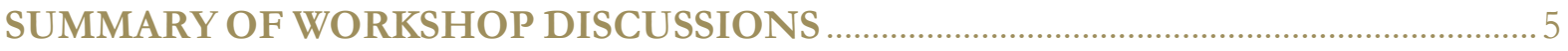

The Value of Research Translation ......................................................................................... 5

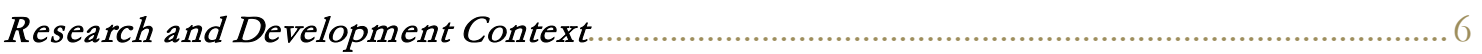

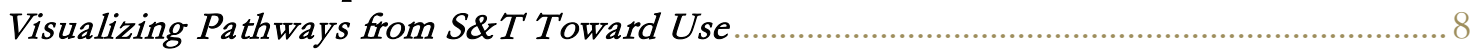

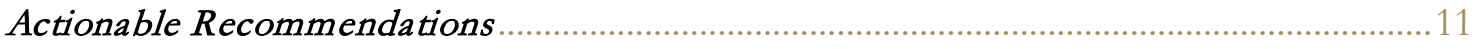

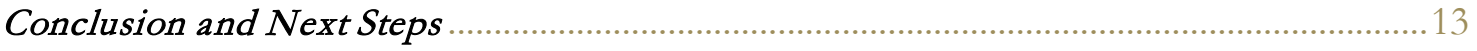

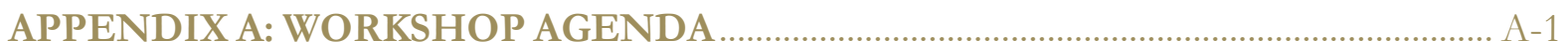

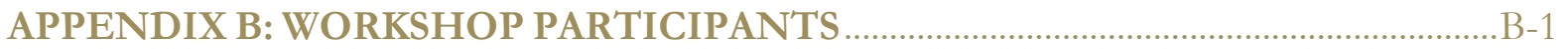

APPENDIX C: DETAILED SUMMARY OF WORKSHOP DISCUSSIONS ..................-1

APPENDIX D: SLIDES FROM LUNCHTIME SEMINAR …........................................ D-1 



\section{Science for Society Workshop- Executive Summary}

Science for Society, a workshop held at the Oak Ridge National Laboratory (ORNL) on September 27, 2011', explored ways to move Laboratory science toward use. It sought actionable recommendations. Thus the workshop focused on: (1) current practices that promote and inhibit the translation of science into use, (2) principles that could lead to improving ORNL's translational knowledge and technology transfer efforts, and (3) specific recommendations for making these principles operational.

This highly interactive workshop struck a positive chord with participants, a group of 26 ORNL staff members from diverse arenas of science and technology ( $S \& T)$, technology transfer, and external laboratory relations, who represented all levels of science, technology, and management. Recognizing that the transformation of

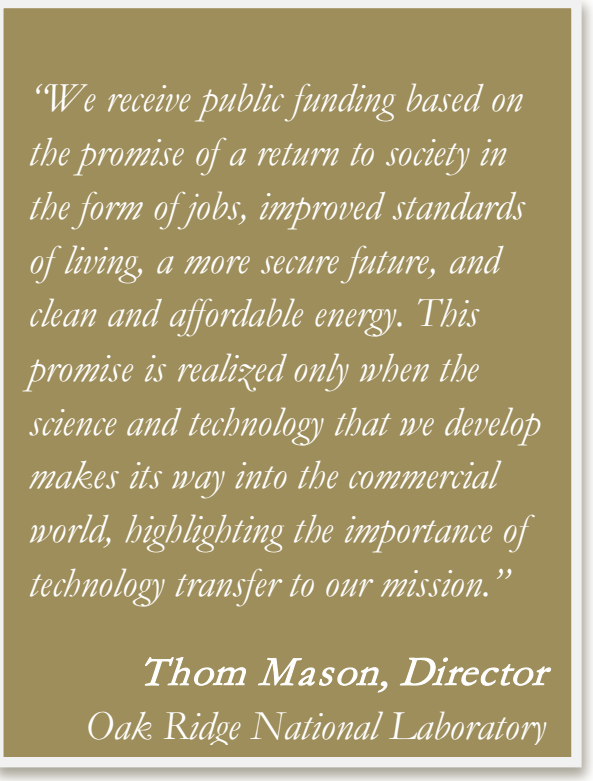
fundamental principles into operational practices often follows a jagged path, the workshop sought to identify key choices that could lead to a smoother journey along this path, as well as choices that created roadblocks and bottlenecks. The workshop emphasized a portion of this pathway, largely excluding the marketplace. Participants noted that research translation includes linkages between fundamental and applied research and development (R\&D), and is not restricted to uptake by manufacturers, consumers, or end users.

Three crosscutting ideas encapsulate workshop participants' observations:

(1) ORNL should take more action to usher the translation of its S\&T products toward use, so as to make a positive national and global impact and to enhance its own competitiveness in the future;

(2) ORNL (and external entities such as DOE and Congress) conveys inconsistent messages with regard to the importance of research translation and application, which (a) creates confusion, (b) poses disincentives to pursue research translation, (c) imposes barriers that inhibit cross-fertilization and collaboration, and (d) diminishes the effectiveness of both the science mission and the translation of that science for use; and

(3) ORNL should design its commitments and actions for helping move science from the Laboratory toward use to align with one another and should integrate them into its institutional culture in such a way as to elevate research translation and application to coequal status with scientific excellence.

\footnotetext{
${ }^{1}$ Funded by the U.S. Department of Energy, Office of Science, Office of Biological and Environmental Research, through its Ethical, Legal, and Social Issues Activity (ELSI), KP1603000.
} 
Participants made several actionable recommendations for enhancing research translation at ORNL, some of which were particular to specific S\&T domains. Among the recommendations that participants agreed apply Lab-wide are to: align metrics and incentives with research translation goals; manage risks and conflicts of interest instead of avoiding them; and create programs (e.g., entrepreneurial leave) that promote interactions between key ORNL staff and industry in ways that complement careers at ORNL. 


\section{Science for Society Workshop-Overview}

\section{Purpose and Goals}

Oak Ridge National Laboratory's (ORNL) Ethical, Legal, and Social Issues (ELSI) Scientific Focus Area (SFA) ${ }^{2}$ convened a workshop at ORNL entitled Science for Society on September 27, 2011. The workshop focused on moving information and products of ORNL's varied science and technology (S\&T) research and development (R\&D) along the pathway toward use and sought ideas and suggestions from ORNL staff members on how to accomplish this goal. It aimed to serve as a vehicle for sharing information and experiences, deriving lessons learned, and articulating realistic recommendations for moving S\&T toward use.

\section{Description of Workshop}

Twenty-six individuals drawn from ORNL's diverse S\&T arenas as well as intellectual property, technology transfer, and partnerships activities attended the workshop.

Participants represented ORNL's bioenergy, climate change, energy efficiency, materials, nanoscale, national security, neutron, supercomputing and computational sciences. They included bench scientists, project and program managers, division directors, and Laboratory Leadership Team members. Participants' responsibilities spanned the gamut from basic science through application and ultimately to commercialization.

The workshop was designed to be highly participatory. To that end, sessions were organized around the following three key questions (see Appendix A for the full agenda):

1. What promotes and inhibits the translation of S\&T from research toward use?

\section{Participants}

- 26 individuals attended.

- Diverse S\&T represented: bioenergy, climate change, energy efficiency, materials, nanoscale, national security, neutron science, supercomputing and computational science.

- Commercialization, intellectual property, technology transfer partnerships, and laboratory external relations also represented.

\section{Focal Issues}

- Factors that promote and inhibit the translation of S\&T from basic research to applied research, and toward practical use.

- Principles/mechanisms that facilitate the translation of mission-inspired S\&T for societal use.

- Realistic, actionable changes that can be implemented at ORNL to improve the ability of missioninspired science to meet societal objectives.

\section{Session goals}

Identify top-three factors, processes/mechanisms, and recommendations:

- In general, and by:

- Phase of R\&D lifecycle

- Kind of S\&T

- Energy vs. environmental application.

${ }^{2}$ Funded by the U.S. Department of Energy, Office of Science, Office of Biological and Environmental Research, through its Ethical, Legal, and Social Issues Activity (ELSI), KP1603000. ORNL's ELSI SFA seeks to add value to the scientific community, by analyzing the evolving societal considerations associated with emerging S\&T. As a part of this activity, the SFA investigates how S\&T discoveries and advances do- or do not—move toward use and acceptance. Thus, while the workshop was a stand-alone activity, it also was an ELSI SFA data-gathering exercise. 
2. What principles/mechanisms can facilitate the translation of mission-inspired S\&T for societal use?

3. What realistic, actionable changes could be implemented at ORNL to improve the ability of mission-inspired science to spawn new industrial products and practices?

Participants were asked to consider and respond to each of these questions in advance of the workshop. Each participant was assigned one of the three questions, with the questions rephrased to home in on examples of particular relevance to the participant. Participants were asked to prepare five-minute responses to their questions, with the goal of sharing their perspectives and jump-starting ensuing discussion. Assignments for each question were spread across different S\&T arenas, both fundamental and applied; intellectual property and technology transfer interests; organizational structures (e.g., centers vs. programs vs. consortia); and potential applications to obtain diverse viewpoints. These short presentations frequently generated questions and lively discussions.

Following each set of short presentations, facilitated, full-group discussions were oriented toward identifying "top-three lists." That is, participants were asked to identify the top three responses to each question so as to focus discussion and strive for a tangible conclusion to each session. To analyze the extent to which responses were broadly relevant or context-specific, participants were asked to consider whether their responses would vary by: (1) phase of R\&D lifecycle (e.g., fundamental versus applied research, if viewed as a continuum), (2) type of S\&T (e.g., neutron vs. computational), and application (energy vs. environmental). Participants were encouraged to speak freely, and informed that exchanges within the workshop would not be attributed to individuals.

There were two keynote speakers. Associate Laboratory Director Martin Keller opened the workshop. He framed the workshop as an experiment with regard both to its structure and potential outputs. In encouraging participants to engage openly with the topic at hand, he noted that the importance of the topic to ORNL management. He also recognized its importance to staff. Keller noted that many people who come to ORNL with the dream of accomplishing something great through their science become disheartened as they face roadblocks. The workshop offered the opportunity to identify a range of roadblocks and offer solutions.

The lunch session featured a presentation by Shaun Gleason, whose professional pathway centers on translational research. His talk presented an overview of his experiences as a scientist, entrepreneur, and manager. He is generally recognized as an example of the type of staff member who epitomizes "closing the loop" on the path from research to production. Appendix D contains Gleason's slides. 


\section{Summary of Workshop Discussions}

As noted above, the workshop was structured around three questions key to improving the translation of science and technology toward use, where "use" means uptake of information, products, and technologies, whether by parties within the Laboratory (e.g., use of Laboratoryproduced basic science by Laboratory scientists and engineers conducting applied R\&D) or beyond the Laboratory (e.g., manufacturers, consumers, etc.). The three questions were: (a) What does and does not work?; (b) What opportunities for achieving improvement work?; and (c) What are actionable recommendations, given the ORNL context? Participants' individual answers to these questions are presented in Appendix C, where they are summarized in Tables 1, 2 , and 3 and then discussed at more length. In this section, we attempt to distill these detailed responses following a thematic format. These themes are: (a) the value of research translation; (b) the ORNL context, (c) concepts for visualizing the pathways from science toward use; and (d) actionable recommendations.

\section{The Value of Research Translation}

The number and diversity of the staff members who chose to participate in the workshop and the energy with which they engaged in discussions attest to the importance they attach to translational research. Individuals cited numerous reasons for the importance of moving scientific knowledge and discoveries along the path from laboratory toward use. Personal and career aspirations of scientists and managers were cited as significant motivators. Participants conveyed that the larger purpose of their scientific research was to benefit society. However, they said that the degree to which the rewards of society's significant investment in science materialize depends on the ability to translate research to use.

Participants also discussed external factors that reflect the value of translating research toward use. While participants noted ORNL's reputation for successful translation, there was consensus that rethinking the traditional approach to research translation could improve the Laboratory's strategic position for the future. By strengthening its reputation for research translation, the Laboratory could better weather future budget and policy uncertainties and maximize opportunities to engage in cutting-edge science. As budgets tighten, ORNL's ability to push science toward society could help secure its future.

Effective research translation was described as important to the global competitiveness of the United States. Whereas the traditional U.S. model of science and technology focuses on pre- 
competitive research to discover basic knowledge, laboratories in other countries-including some with economies that are emerging as our competitors-are structured to achieve national goals through direct interactions among scientists, developers, and manufacturers. Participants suggested that reevaluating the current U.S. model for conducting science is a way to enable translational R\&D, position ORNL as a leading organization and improve economic competiveness of R\&D internationally.

\section{Research and Development Context}

Research and development $(\mathrm{R} \& \mathrm{D})$ context has two components. One component is internal, that is what happens within ORNL. Another component consists of those strong external forces that shape what happens within the Laboratory. Participants typically referred to the programs that fund ORNL S\&T and their attendant expectations as key external forces, but sometimes referred to higher-level organizations such as agencies or Congress.

Participants generally agreed that sponsors' interests and directives influence the extent to which research translation or application are emphasized by ORNL researchers, programs, and managers. From that standpoint, participants stated that sponsors' clear and consistent expressions of interest in research translation would promote research translation. As one example, when Secretary

Explicit expressions of support for research translation, when aligned with performance metrics and rewards, would create an $R \& D$ context conducive to research

translation. Consistency of goals among DOE offices, other sponsors would help to establish translational nature of $R \& D$ in the Laboratory. Regardless, Laboratory management can take unilateral actions that promote a research-translationfriendly environment. Chu told Bioenergy Research Center (BRC) managers that peer-reviewed publications were necessary but insufficient for "success," patenting and licensing (key markers of research translation) received far greater emphasis. ORNL's BioEnergy Science Center (BESC), for instance, produced more disclosures than in the previous three years combined, at least partly due to the Secretary's missive.

This same concept was expressed when participants talked about the Laboratory itself. They regularly said that clear, consistent communication about the importance of research translation is important. They went further, though, to emphasize that messaging alone could prove ineffective in promoting research translation unless it is combined with compatible performance metrics and incentives. 
Participants spent considerable time discussing aspects of Laboratory context that pose challenges to effective research translation. The most frequently mentioned obstacle was the disincentive to pursue translational research that grows out of ORNL's strong emphasis on basic science. Participants said that performance metrics at ORNL typically reward peer-reviewed publications and sometimes treat other activities as distractions. One consequence is that scientists may minimize or cease involvements that compete with publishing. Participants cited several examples, including the following: (a) pushing discoveries toward use requires time that otherwise could be spent developing high-impact, peer-reviewed publications; (b) collaborating with industry (seen as among the most direct ways to move S\&T toward use) takes time away from producing publications and can jeopardize funding from sponsors who emphasize basic research; (c) taking time off from the "bench" to work with industry poses the risk of having no funded work at ORNL once the outside assignment is completed; and (d) using specialized equipment such as beam lines to test proof-of-concept ideas relevant to use in industrial or similar settings detracts from the "real science" that can lead to peer-reviewed publications.

Participants closely linked these disincentives to the larger issue of ambiguities and mixed messages sent and received at multiple institutional levels regarding organizational goals. For example, participants suggested that, although Laboratory management says it values translational research, it conveys more strongly a bias toward basic science. One expression of this bias is how fundamental scientific research and high-impact publications regularly are depicted as key to the institution's core mission in written and oral communications, while patents and innovation achievements_-if mentioned explicitly_ generally are presented as secondary. Participants from directorates and divisions with a more applied focus noted that they felt like lesser citizens of the Laboratory and not part of the organization's mainstream focus, for example "like the ugly stepchild of the family." More generally, applied and technology transfer participants said that they, like other ORNL employees, receive conflicting messages about the degree to which the Laboratory in fact values research translation.

Discussions about the context of ORNL's S\&T naturally led to considerations of external influences on the Laboratory. Thus, participants said that ORNL's bias toward basic science stems from the fact that it formally is a DOE Office of Science (SC) laboratory. They noted that, because of SC's mission, much funding supports fundamental research. Participants suggested that collaborating too closely with industry can jeopardize some SC funding. Further, they said that whereas SC sometimes publicizes the applications that result from its funded research, SC seldom funds these outcomes directly. As one participant put it, "SC likes technology transfer, but they want it to be a surprise." This situation is but one example that participants used to make the point that sponsors, like Laboratory managers, also can send mixed messages about the value of research translation.

Workshop attendees noted that other sponsors, such as the Office of Energy Efficiency and Renewable Energy (EERE), and some work-for-others (WFO) sponsors, have a more application-driven research agenda than SC. These sponsors typically come to ORNL with 
specific problems they want to be solved and may neither require nor want high-impact peerreviewed journal articles to emerge from the work they fund. One participant indicated that WFO funding could be used strategically as a vehicle for engaging in research translation. While a number of participants indicated that these sorts of applied efforts can help the Laboratory demonstrate a visible, positive impact on society, they also said that such achievements often seem not to be appreciated during in-house evaluations of scientists' performance.

Participants indicated that meeting customers' needs is, perhaps, the most crucial factor affecting the degree to which research is translational. However, there was confusion as to who ORNL's customers really are. While the most obvious answer was "our sponsors" (especially DOE-SC), participants also identified Congress — which establishes sponsor priorities through appropriations, the private sector-which has strong influence over Congressional decisions, and the public as customers.

\section{Visualizing Pathways from S\&T Toward Use}

Much workshop discussion centered on how S\&T might be conducted so as to flow more readily and effectively from Laboratory toward use. This conversation wavered back and forth between alternative conceptions of how $\mathrm{S} \& \mathrm{~T}$ currently is versus how it could or should be conducted. Although focusing on ORNL, this discussion addressed the conduct of S\&T well beyond the borders of ORNL and the U.S. (see Appendix $\mathrm{C}$ for more detailed descriptions).

Conduct of Science. Starting from a variant of the Vannevar Bush model of science-to-society processes, Figure 1 was presented to participants
Participants described what we call an "ushering" model for moving S\&T toward use-an active responsibility to nudge information, results, and products the next step toward use. $A$ variety of extant and experimental approaches at ORNL and elsewhere aim to effect better ushering. to spur discussion. Participants proposed several alternative conceptions and images to describe translational processes, and identified a number of barriers to translation. The linearity of the Vannevar Bush model was rejected by nearly all participants. Although one participant noted its success in securing Congressional funding for scientific research over the past several decades, most participants depicted the model as inaccurate, particularly in its absence of feedbacks and interactions. An alternative conceptual model raised by attendees was the "tire track" model, which describes basic science, $\mathrm{R} \& \mathrm{D}$, and application development as occurring on parallel tracks, noting that for important break-throughs to occur these tracks must intersect. Another participant said that translational research is interactive and integrated, such that it best can be described by a yin-yang diagram. 


\section{SCIENCE FOR SOCIETY: \\ TRANSLATING SCIENCE TO SOCIETAL BENEFIT}

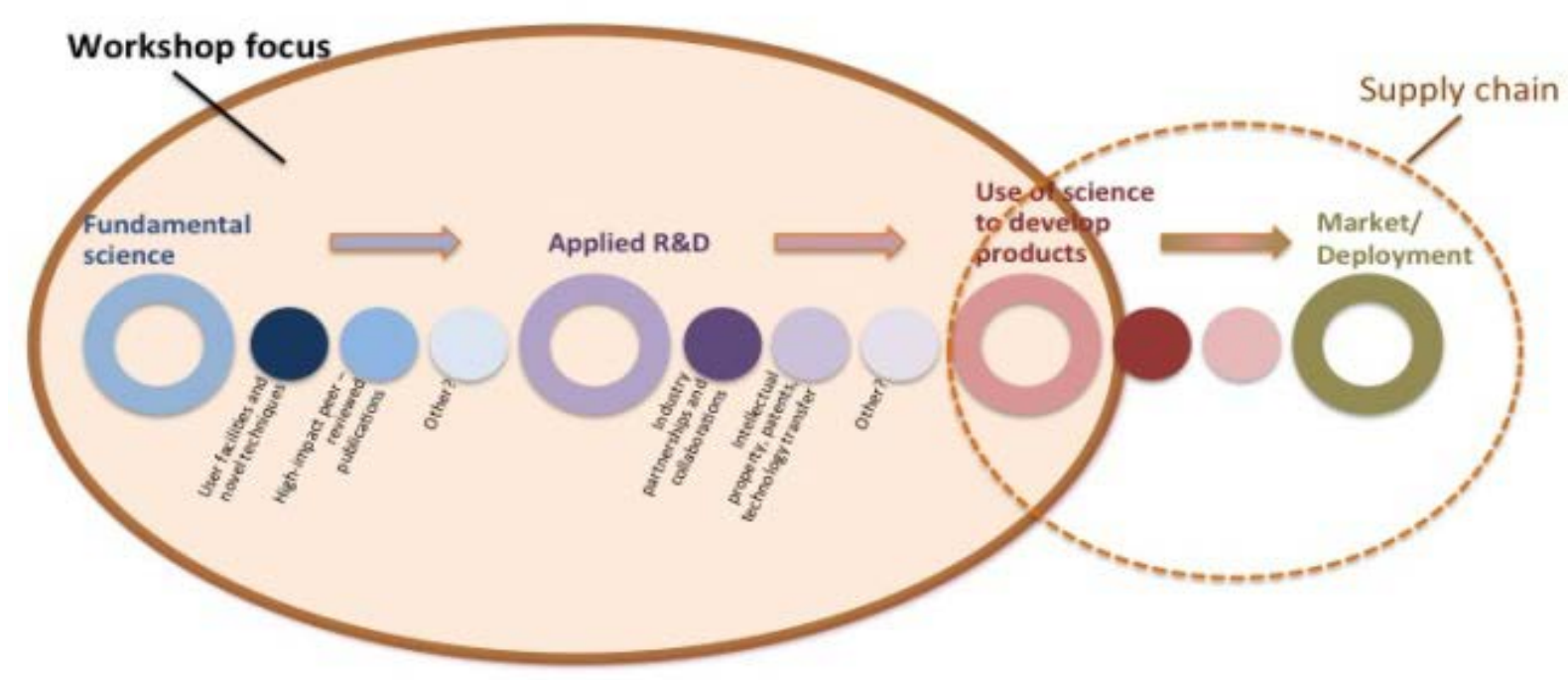

Figure 1: Traditional model used to describe the conduct of science. This model was presented at the workshop to solicit feedback from participants.

Similarly, participants discussed several ways to describe the organizational character of the S\&T enterprise that could elucidate alternative ways to encourage truly translational R\&D.

Participants used "ecosystem" and "cluster" analogies to describe organizational ways to translate high quality science into useful applications. They cited Boston/Cambridge, Silicon Valley, and the Research Triangle as examples. These regions are characterized by a critical mass of basic research institutions, high-tech industries, and a skilled workforce, all in close enough proximity to facilitate interaction and the movement of workers among the different components. Participants said that the ability of personnel to move from one role (e.g., basic research) to another (industrial application development) and then back again is important to the success of these regional centers. Participants described ORNL, in contrast, as an "island ecosystem" since its geographic region lacks a strong base of diverse, high-tech industries, and associated technically skilled workforce. As one participant observed, "When people move from here [ORNL], they move to [for example] Vancouver, and they don't come back."

Participants proffered images to describe dis-connections between the development of S\&T products and the uptake of those products by others, especially "valley(s) of death" and "overthe-fence" analogies. The former was described in terms of gaps between products and their uptake, whether the valleys occur between fundamental and applied research or between technology development and adoption. Participants described the over-the-fence concept in terms of the tendency of researchers - both basic and applied — to define an end to their own efforts or responsibilities, and leave it to some unidentified outside party to find their product, pick it up, and move it forward. 
Ushering. During the course of the workshop, as participants discussed and reached general consensus on measures that could be enacted at ORNL to foster the translation of S\&T toward use, they suggested ideas that we combine into an alternative model that we label "ushering." We wove key elements raised by attendees into this model. For example, ushering centers on the Laboratory taking active responsibility for moving the information, results, and products of its research toward use. It entails changes in how $S \& T$ research and development are conducted, in institutional organization and management, and in the structure of incentives and rewards.

Based on workshop discussions, ushering would purposefully blur the distinction between fundamental and applied scientists. Performance would be measured not only by researchers' ability to publish in high-impact journals but also by their conference presentations, collaborations with industry, disclosures, patents, and licenses. Managers would be charged with promoting research translation and would be rewarded for the successes of their staff. Participants suggested that user centers could be encouraged to bring in proprietary research that is closer to application so that results reach application more quickly, instead of focusing heavily on research that can be published in open sources. Some participants indicated that, through these kinds of practices, industry would come to recognize ORNL as an indispensible asset for its success.

Several participants said that successful research translation (especially technology transfer) requires strong relationships with potential users, and suggested that the Laboratory community more actively strive to make and nurture these relationships. However, the generalized importance attributed to customers' needs was countered by participants' cautionary examples of when the sponsor or customer may have faulty information or unrealistic expectations. For example, during the anthrax scare of 2001, sponsoring agencies called on scientists to develop a technology that could detect toxic bacteria in 10 minutes-a goal ORNL scientists did not think could be achieved within the sponsor's specified two-year timeframe. These scientists then had to decide whether to compete for funding despite their reservations, and compete with applicants from research institutions with fewer qualms about promising rapid success. A decade later a successful technology still has not been developed.

Attendees also cited interactions among researchers within and beyond ORNL, and between researchers and private sector organizations as crucial for research translation success. They described recent DOE and ORNL organizational experiments that are intended, in part, to create institutional arrangements that foster these interactions and, therefore, research translation. A prime example is DOE's creation of BESC and other BRCs to achieve the societal goal of dramatically increasing bio-fuel production. These centers bring fundamental biologists, engineers, industrial representatives, and others into collaboration. While the various institutions that make up BESC are dispersed across the country, they form a "virtual cluster." Participants suggested that this type of cluster may be hard to duplicate because of the large funding involved. However, other participants described their own efforts to create a research cluster, by (1) deliberately hiring staff outside the center's mainstream expertise, and (2) road-mapping to 
address applied problems. Other examples raised by participants include ORNL's recent reorganization of two directorates to bring together fundamental and applied researchers into single organization with one goal of achieving new levels of research translation. One participant discussed a similar "experiment," but on a group level, in a case where a formerly applied research group "inherited” some basic scientists. Participants said that adequate funding, time, and patience are important for creating these kinds of successful organizational interactions.

\section{Actionable Recommendations}

Throughout the workshop, participants offered actionable recommendations to encourage the movement of Laboratory S\&T toward use. Some recommendation were targeted at Laboratory-wide applications, while others were deemed more appropriate for specific S\&T applications. Recommendations applied variously to DOE, ORNL leadership, division and sub-division management, and to intellectual property, commercialization, and
If workshop discussion could be boiled down to a single point, it would be that successful research translation cannot be left to individual volition and luck; it must be pushed and supported by the Laboratory. technology transfer specialists. Some recommendations specifically concerned resource allocation and publicity. All of the recommendations can be found in Appendix C. Here we highlight those that garnered broad support during the workshop.

Push and support research translation. If workshop discussion could be boiled down to a single point, it would be that successful research translation cannot be left to individual volition and luck; it must be pushed and supported by the Laboratory.

Convey value of research translation \& align performance metrics. Perhaps the key recommendation for how the Laboratory should push and support research translation was for ORNL leadership to convey clearly the value it places on research translation and to align performance metrics with that value. Workshop participants repeatedly made the point that, "It's not enough to say the Lab [Leadership] supports translational research; it also needs to provide institutional support." Participants encouraged the Laboratory to incorporate translational values into its mission statement, to define related goals and objectives in its strategic objectives and business plans, and to support and promote research translation in Seed Money and LaboratoryDirected R\&D decision-making. Further, participants recommended that, if the Laboratory truly values research translation, the prestige and rewards associated with high-impact journal articles should be matched by prestige and rewards for patents, licenses, and disclosures. More broadly, participants said that disincentives to research translation (e.g., risks to funding sources) should be identified and removed. 
Reinstate part-time entrepreneurial leave program. Participants strongly endorsed reinstatement of part-time entrepreneurial leave as a method to foster better exchange between the Laboratory and industry. Currently, a researcher who wants to pursue development of a discovery or technology must do so outside the context of employment at ORNL. In addition to the risks normally associated with developing a new product, these researchers also risk losing their connection to the Laboratory and the body of work they have developed. There was consensus among the participants that part-time entrepreneurial leave would minimize these risks and, thereby, remove a significant barrier to translation.

Related to this point, participants also recommended that the Laboratory work to manage its risks, not avoid them. This recommendation evolved from a discussion in which participants identified "avoiding conflicts of interest" as one reason that ORNL canceled its part-time entrepreneurial program.

Use monetary incentives and recognition. In all three sessions of the workshop, some participants maintained that the strongest incentive for pushing science toward use is through monetary incentives to individual researchers who engage in this process. In contrast, one participant noted that, in his experience, "rewards, promotions and accolades in front of their peers are much better in the long run than a check." Both financial incentives and recognition might be considered as tools for driving science toward use.

Make user centers more research-translation-friendly. Participants recommended that user centers be publicized and operated in ways that better support translational research. The capabilities of the centers should be promoted more energetically to industry and made more easily accessible to industry. Metrics measuring user center effectiveness should be changed accordingly. The current practice of preferentially providing facility access to users who agree to publish basic scientific findings in open literature should be altered to give more support for users pursuing application development. Methods to allow quick, proof-of-principle testing for industrial users should be incorporated into operational strategies that currently favor longerterm research into fundamental issues.

Assure same intellectual property rights for all parties in Cooperative Research and Development Agreements (CRADA). Participants pointed out that CRADAs currently allocate intellectual property (IP) rights differently for industrial partners, subcontractors, students, and ORNL staff. As a result, industrial partners may not retain sufficient control over the IP to protect their interests, and, thus, may be less likely to enter into a CRADA. Assuring the same IP rights for all parties to the agreement was recommended to remove a disincentive for industrial participation.

Adopt organizational structures and practices that are conducive to research translation. Finally, the workshop discussion highlighted the importance of institutional and organizational arrangements. Some organizational structures have been shown to be conducive to research translation. Successful organizational experiments have shown that staff immersion can promote 
collaborations within the Laboratory between fundamental and applied researchers-even among those in different fields. Participants also recommended that organizations strive to create policies that encourage innovation and seek and remove policies that, perhaps inadvertently, stifle that innovation. One participant suggested that there are activities currently underway at ORNL to explore some of the concerns and recommendations discussed during the workshop.

\section{Conclusion and Next Steps}

Participants in the Science for Society Workshop represented a wide diversity across ORNL's S\&T, S\&T management, and intellectual property, technology transfer, and commercialization enterprises. Participants seemed to welcome the opportunity to exchange information and ideas directly among a group of people with whom they normally would not interact. There was a remarkable degree of forthright discussion among participants about issues they seemed to be pondering and grappling with in their day-to-day professional lives. Participants conveyed strong support for research translation, some of which appeared to derive from their pride in their own work and in ORNL's reputation. They, indeed, expressed a belief that ORNL's publicly funded science should provide benefits for society. Most workshop attendees suggested that they would offer their support to changes that would help integrate the Laboratory's more applied activities into its current basic science focus, a process that would confer equivalent status and expectations across the spectrum of ORNL's basic and applied S\&T initiatives and contributions.

Workshop discussions explicitly addressed the context of ORNL's operations. Thus, participants regularly made reference to external entities that shape the Laboratory and its research translation endeavors. Attendees often switched their points of reference between within- and outside-ORNL perspectives. Thus, they frequently noted how external sponsors, especially DOE, or the makeup of nearby academic and private-sector organizations constrain and potentially provide opportunities that shape activities and actions at ORNL. Conversations reflected nuanced thinking. For example, while participants conveyed how the Laboratory's emphasis on S\&T might provide disincentives for research translation, they also noted the potential danger for ORNL in elevating science translation at the expense of science production.

Despite an institutional context that depends on external sponsors and relies upon fundamental science, attendees strongly conveyed the sense that ORNL should take more responsibility for effecting research translation. They regularly indicated that statements of support are necessary, but insufficient. Rather, they highlighted the importance of clear, consistent messages that are operationalized in performance metrics and reward structures, programs like part-time entrepreneurial leave, in-house funding, and the like. 
Workshop participants have been given the opportunity to review this report and its Executive Summary. Participants expressed a desire to share the executive summary with ORNL's Leadership Team and, perhaps, others within the Laboratory. From that point, next steps within ORNL would be determined. Beyond ORNL, workshop conveners presented a summary to their SC sponsors and other Office of Biological and Environmental Research program managers. Conveners also will use workshop notes as data from which to develop posters and other publications both for their own scholarly community and, as a form of research translation, for the scientific community. The authors plan similar workshops in FY 2012 and FY 2013, at another national laboratory and an academic research center, respectively. These additional workshops will help the authors analyze the extent to which findings from this workshop are particular to ORNL or are more broadly applicable. 
APPENDIX A:

WORKSHOP AGENDA 



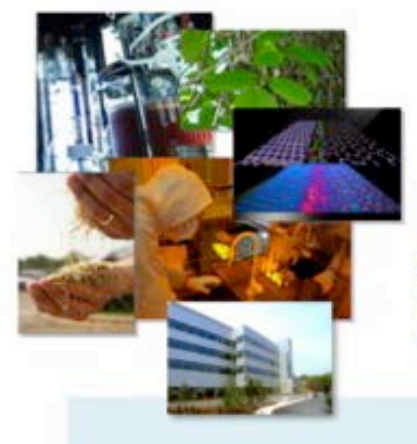

\section{Science for Society Workshop \\ September 27, 2011 ORNL Clinch River Cabin}

Sharing information and experience to derive lessons learned and recommendations for moving Laboratory science and technology (S\&T) toward use across ORNL's varied emeraing technologv R\&D arenas

\section{Workshop Agenda}

8:30 a.m. Welcome and introductions

Martin Keller (Associate Laboratory Director, Energy and Environmental Sciences)

Workshop goals and agenda

Note: Continental breakfast will be available beginning at 8 a.m.

9:30 a.m. Sharing knowledge

What promotes and inhibits the translation of S\&T from research toward use within and across (a) kinds of S\&T (e.g., fundamental nanoscale science vs. applied energy efficiency R\&D; (b) how R\&D is organized (e.g., centers vs. programs vs. consortia); and (c) different potential applications (e.g., energy vs. environment or consumer vs. non-consumer goods)

- Short presentations-selected participants' perspectives to jump-start discussion

- [break]

- Structured, full-group discussion to identify what attributes promote or inhibit success in moving S\&T from research toward use

11:30 a.m. Working lunch

Shaun Gleason (Group Leader, Imaging, Signals, and Machine Learning), Translational Science for Imaging R\&D: A Group Strategy and Success Stories

1:00 p.m. Building a community of practice

What practices/mechanisms can facilitate the translation of mission-inspired S\&T for societal use? How could these practices/mechanisms be formalized - strategic elements, focus, temporal dimensions, etc?

- Short presentations-selected participants' perspectives to jump-start discussion

- Structured, full-group discussion to identify best practices, the most significant obstacles

3:00 p.m. Break

3:15 p.m. Recommendations

What realistic, actionable changes can be implemented at ORNL to improve the ability of mission-inspired science to meet societal objectives?

- Short presentations - selected participants' perspectives to jump-start discussion

- Structured, full-group discussion to identify the "best bet" near- and longer-term targets for improvement-generally, and strategically

4:15 p.m. Wrap up and next steps

4:30 p.m. Adjourn 

APPENDIX B:

WORKSHOP PARTICIPANTS 



\section{Appendix B: Workshop Participants}

Young Sun Baek, Energy \& Environmental Sciences Directorate; Energy \& Transportation Science Division; Power and Energy Systems Group

Hassina Bilheux, Neutron Sciences Directorate; Neutron Scattering Science Division; Powder Diffraction Group

Jeff Cornett, Partnerships Directorate; Industrial \& Economic Development Partnerships Manager

Mitch Doktycz, Energy \& Environmental Sciences Directorate; Biosciences Division; Biological and Nanoscale Systems Group Leader

Shaun Gleason, Energy \& Environmental Sciences Directorate; Measurement Science \& Systems Engineering Division; Imaging, Signals, \& Machine Learning Group Leader

Johney Green, Energy \& Environmental Sciences Directorate; Energy \& Transportation Science Division Director

Jud Hightower, Legal Directorate; IP Managing Attorney

Patrick Hughes, Energy \& Environmental Sciences Directorate; Energy \& Transportation Science Division; Building Technology Research \& Integration Center Director

Gene Ice, Physical Sciences Directorate; Materials Science and Technology Division Director

Ilia Ivanov, Physical Sciences Directorate; Center for Nanophase Materials Sciences; Functional Hybrid Nanostructures

Gary Jacobs, Energy \& Environmental Sciences Directorate; Environmental Sciences Division Director

Martin Keller, Associate Laboratory Director, Energy \& Environmental Sciences Directorate
Tom King, Energy \& Environmental Sciences Directorate; Energy Efficiency \& Electricity Technology Program Director

Lynn Kszos, Neutron Sciences Directorate; NScD Strategic Planning \& Administration Manager

Nick Lavrik, Physical Sciences Directorate; Center for Nanophase Materials Sciences; Nanofabrication Research Laboratory

Betty Mansfield, Energy \& Environmental Sciences Directorate; Biosciences Division; Genome Management Information Systems Group Leader

Tony Palumbo, Energy \& Environmental Sciences Directorate; Biosciences Division Director

Mike Paulus, Partnerships Directorate; Technology Transfer Director

Jim Roberto, Associate Laboratory Director, Science and Technology (S\&T) Partnerships Directorate

Blair Ross, Global Security Directorate; New Concept Development Senior Program Manager

Mike Simonson, Neutron Sciences Directorate; Neutron Scattering Science Division; Materials Chemistry Senior Scientist

Renae Speck, Partnerships Directorate; Senior Commercialization Manager

Ben Thomas, Global Security Directorate; Homeland Security \& Advanced Programs, SERRI/CARRI Program

Lakeisha Walker, Neutron Sciences Directorate; Neutron Scattering Science Division; HFIR Support Team

Jack Wells, Computing \& Computational Sciences Directorate; National Center for Computational Sciences Director of Science

Brian Worley, Computing \& Computational Sciences Directorate; Computational Sciences \& Engineering Division Director 

APPENDIX C:

DETAILED SUMMARY OF WORKSHOP DISCUSSIONS 



\section{APPENDIX C: Detailed Summary of Workshop Discussions}

The workshop was organized into three sections, each exploring a key question about the translation of research toward use at Oak Ridge National Laboratory. Participant input was recorded on flip-charts and is summarized in this appendix. First we present tables summarizing responses to the three main questions posed during the workshop and a high-level summary of other workshop outcomes. Tables are followed by more detailed descriptions of points participants made during the workshop. Some of that discussion duplicates material presented in the main body of the workshop summary.

\section{Question 1: What promotes and inhibits the translation of S\&T from research toward use?}

\section{Factors that Promote}

- Consistent favorable political climate from Congress and administration and consistent policy climate from DOE and ORNL

- Common goal for DOE's Basic Energy Sciences (BES) and applied DOE office (EERE)

- Integration of input from sponsors (DOE) and potential application developers into research design and conduct; constant communication

- Clusters/ecosystem that facilitate translational research

- Commonality of vision, mission, objectives, measurements of success, and resources

- Understanding customers and meeting their needs

- Give higher value to "management for translation"

- Management commitment of resources to provide incentives to researchers, application developers, tech transfer experts (e.g., LDRD funding directed toward translation)

- Management demonstration of value of moving toward use (e.g., rewarding patents)

- ORNL emphasis on translational outcomes beyond DOE's emphasis

- Industry awareness of value of basic research (a result of Laboratory collaboration with industry)

- Engaged technology developers throughout translation (basic and applied R\&D staff)

- Sense of ownership by basic scientists, application developers, tech transfer experts

\section{Factors that Inhibit}

- Lack of consistency in policy/political climate

- Different expectations from sponsors (BES wants papers; EERE wants to meet metrics of technology transfer)

- DOE doesn't "do" research translation (with some exceptions); DOE "won't help"; Throwing publications or patents over-the-fence

- Metrics that only emphasize publications

- Lack of funding to cross "Valleys of Death"

- Overemphasizing efficiency; narrow focus on publications

- Lack of incentives for translation within ORNL

- Unrealistic sponsor/user expectations (e.g., expectation that real-time chem/bio detector could be developed quickly)

- Lack of consistency of what is valued at ORNL (e.g., papers/publications vs. technology transfer)

- Slow time scale compared to industry's demands

- Role of management for translation undervalued/underutilized; fear of conflict of interest; loss of good employees; extra work associated with translational research

- Lack of feedback in terms of market demands

- Lack of ownership of idea/technology

- Contacts that won't develop into productive relationships 


\section{Question 2: What practices and mechanisms can facilitate the translation of mission-inspired $S \& T$ for societal use?}

\section{Most Needed Practices/Mechanisms}

- Clear support for translation from Laboratory management

- Expand "measures of success" (metrics) to include translational objectives (applies to both ORNL and DOE); Metrics that reward partnership with industry

- Expand definition of performance metrics from high-impact publications to include technical conference presentations, etc.

- Better utilization of existing industry relationships to introduce other ORNL capabilities; Identify translational needs/opportunities that match Laboratory capabilities

- Attract "high impact" users to user centers; Industry reviewers for user centers

- Tailor straightforward solutions and communications for industry; Insert science into competitive research in industry

- Rapid testing/prototyping-especially if valued by organization or sponsor and not seen as competing with fundamental research

- Safety nets for entrepreneurial researchers to translate research; Part-time entrepreneurial leave (cross-cutting need)

- Time for researchers and managers to step away from research to think creatively to facilitate translational research

- Integrating customers, operations and society with S\&T; Better understanding of how to integrate social science and social networking to address societal needs with S\&T

- Establish opportunity for researchers to move among academia, industry, and Laboratory within synergistic innovation clusters

- Process to facilitate the creation of innovation clusters and provide management support

- Incentives for researchers to engage in translation (need differs between basic and applied researchers)

- Some sciences (e.g., environmental) are not known for their invention disclosures; need to discuss how to make them more accessible to industry

- Coordinated efforts to take ideas from basic research to application development/Someone to bridge valley of death

- Focus on applied aspects of research that may not be Science or Nature material

- Communicate effectively with the public to inform their perception of emerging technology 


\section{Question 3: What realistic, actionable changes can be implemented at ORNL to improve the ability of mission-inspired science to meet societal objectives?}

\section{For DOE/Sponsor}

Partnership
- Become market-driven to address customer needs (customers being DOE and industry)

- Shift focus from pre-competitive market to translational market

- Provide incentives and remove disincentives associated with conducting translational research

- Make user centers known to industry and more accessible for industry (involves changing performance metrics)

- Make changes to CRADA language so that industry partners are guaranteed same rights from subcontractors and students as from ORNL staff

\section{Leadership}

- Provide incentives and remove disincentives associated with conducting translational research

- Manage risk and conflicts of interest, don't avoid them

- Re-invigorate part-time entrepreneurial leave program (and similar programs) to encourage research translation

- Create organizational structure to facilitate more effective research translation-take out programs and look across whole lab

- Find common vision and rework metrics accordingly

- Develop clusters (or ecosystems) internally and via partnerships/collaborations

- Value management (group leaders) give them time to drive translation instead of all their time on research

- Adopt an $80 / 20$ rule, $80 \%$ of time on work, $20 \%$ of time on creative thinking

\section{Resource Allocation}

- Use discretionary and incentive funds where appropriate to encourage research translation

- LDRD money should be focused on translational research, LDR to D

- Seed money to fund projects nearing application development
- Better understanding of industry's needs, focused agenda based on particular company's needs instead of standard "dog and pony show"; Improve communication with industry-listen to potential customers to see the needs and ask questions

- Develop stronger strategic partnerships...earlier

- More embedded partnerships within ORNL staff

\section{Public Relations/Publicity}

- Better use of science writers in communications department

- Improved promotion/advertising/marketing of ORNL technologies

- Engage targeted customers earlier in $R \& D$ and more often

- Website that highlights our capabilities and is easily accessible and sensitive to the fact that people may search under keywords different from our standard terms

\section{Management}

- Motivate staff: staff immersion (e.g., different disciplines on the same team)

- Train staff to be translational researchers

- Maintain better records of our successes

\section{Principal Investigators}

- Maintain better records of our successes

- Accessible writing for customer (“end user")

- Take greater ownership over research

- Better understanding of the public perception of their work 


\section{Other key outcomes and ideas}

\section{Suggested Next Steps}

- Make presentation to ORNL leadership team

- Circulate workshop report and, especially, executive summary, to ORNL leadership team

- Re-check for progress in future (e.g., 6 months)

\section{Other Key Ideas Noted on Flip Charts}

- Innovation: Ecosystem and Process

- Different approaches of Apple vs. Microsoft (Apple integrates translation into its process, while Microsoft leaves it to others)

- Translation process is not linear, involves/needs feedback

- Strategic planning vs. Institutional planning: reference to Weinberg's model that strategic planning (e.g., roadmap) works if the method can be defined (e.g., build a reactor), while institutional planning is appropriate if the method is unknown (e.g., curing cancer)

- Notion of "use" is very broad

- Two models of communication/education (societal context and Laboratory strengths): (1) society influences politics, which determines policy, which guides the sponsor, which directs the Laboratory; (2) Laboratory strategy influences the sponsor, which also is guided by policy/politics.

- "Ownership" of a problem/technological motivation/sociological problem

- Interaction between proprietary project and type of user facility/ how "close" science is to application

- Need different metrics for measuring research translation

- How to connect basic to applied research

- Did not discuss public acceptability, which ties to communications/education

- Laboratory strategic planning drives LDRD and other planning. Does it trickle down in other ways?

- Need to communicate the risks associated with a technology to translational partners 


\section{More detailed summary of workshop discussion}

\section{Management Matters}

- Group leaders and division directors need to be allotted time to facilitate translational research

- Upper-level managers who are able to influence Laboratory policy need to express clearly the notion of translational research as a priority and provide incentives to drive this change toward effective research translation

\section{"If we truly value a change in}

direction, to do this translational

stuff, we have to give our group

leaders time to manage, not just

research."

- ORNL responds strongly to signals from sponsors, but current metrics encourage focus on precompetitive basic research rather than pushing science and technology to market.

\section{Market Push and Pull}

- Translation of science toward use involves both push from the science side and pull from the development side. The workshop participants identified the following pushes and pulls:

o Existing

- Researchers in basic fields often are encouraged to increase their publications or conference proceedings rather than promote S\&T translation.

- Metrics rewarding researchers for publications and funding

o Needed (Recommended)

- Educational partnerships so universities to focus on translational research; train staff to be translational researchers; adopt $80 / 20$ rule where staff work 80 percent of time and 20 percent of time thinking creatively on the job (transfer ideas, partnerships and activities); and incentives for translational research such as parttime entrepreneurial leave which is more secure than entrepreneurial leave of absence.

- Create demand by making ORNL capabilities known widely (especially to industry); expand Laboratory Directed Research \& Development (LDRD) into LDR-to-D as a translational funding source; strengthen Partnerships' understanding of PI research as it relates to market demands; and focus communication style to intended target audience

\section{Unidentified Customer}

- ORNL has multiple "customers" and often receives multiple signals as to promoting translational science. The discussion over which groups would benefit from ORNL's “customers" ranged broadly from industry to society. DOE funds projects, using dollars appropriated by Congress, which is driven by the public, for example, the Chief Executive Officers (CEOs) from industry. 


\section{Barriers/Stove Pipe/Structural Challenges}

- No incentive to take greater ownership, metrics do not account for translational research

- Rules/signals from sponsors may discourage basic researchers from collaborating with industry; lost funding from DOE

- No provision to take part-time entrepreneurial leave, too risky of an endeavor for principal investigator to take full-time entrepreneurial leave of absence

- DOE programs (such as BES and EERE) operate independently of one another, and there is little incentive to promote cross-program communication; thus little communication within ORNL.

- Fundamental and applied science do not communicate or collaborate often

- Chain of command may not interact with ultimate customers

- Laboratory representatives are often focused on select programs instead of the wider Laboratory, so visitors are subject to multiple presentations instead of receiving a single presentation on the capabilities of the Laboratory as a whole.

\section{Translational Research}

Several participants noted that ORNL has a reputation for being effective in translating science to use. But, there was a consensus that measures could be taken to improve significantly on that success. Some participants noted that translational science that makes a difference in society should be part of a national laboratory's purpose. Others noted that success in this area would position the Laboratory strategically to withstand changes in Congressional and DOE priorities and leadership. It was also pointed out that improved success would support national competitiveness, since other nations have adopted approaches that move new science and technologies to the market more quickly than in the U.S.

Several themes emerged from energetic discussions on how these and other barriers could be overcome. Principal themes included:

- the need for strategies and practices to "usher" science from the Laboratory toward use;

- the importance of recognizing how will respond to approaches requiring risk taking when management is typically risk averse;

- recognition that translation of science toward use involves both push from the science side and pull from the development side;

- the importance of effective communication among all players in the progression from laboratory to use; and

- differences between the translational environments and approaches of basic scientists and applied researchers. 


\section{Strategies and Practices for Ushering Science from the Laboratory Toward Use}

Workshop participants identified numerous possible institutional changes that could improve the Laboratory's effectiveness in moving science toward use. All of these changes would take place within the context of the Laboratory's external environment. This environment is defined by Congressional appropriations and DOE funding allocations, all of which are influenced, in turn, by public attitudes and business priorities. One participant noted that DOE does not appropriate funds, Congress does; and business leaders have a strong voice with Congress. Another agreed, saying that if CEOs told Congress that they could not do without the SNS, full operational funding for the facility would be assured. Sponsor priorities also strongly influence how much emphasis researchers place on translational efforts. One participant recalled a program that, over a three-year period, produced numerous publications but few licenses because the DOE sponsor emphasized basic science. In the fourth year, the sponsor changed the program focus, saying "forget about publications; what impact have you had on industry?" Researchers responded with a dramatic increase in disclosures. Whereas there were 24 disclosures during BESC's first three years (combined), there were 59 disclosures in its fourth year.

\section{Creating a culture that supports translational research}

Recognizing the larger context within which the Laboratory functions, much of the workshop discussion dealt with internal measures ORNL could take to foster the translation of science toward use. Most fundamentally, participants talked about the need for a culture change at the Laboratory, led by top management. There is a perception that ORNL emphasizes basic science over applied research and development and high-impact publications over patents and licenses. Participants encouraged incorporating translational values into the Lab's mission and defining related goals and objectives in the strategic and business plans. Such high-level support, they felt, would foster a culture that promotes translational research through appropriate incentives and acceptance of the risks such research entails.

Some participants reported that their divisions had a more applied orientation and valued technological development at least as highly as basic science. Some of them felt, however, that this orientation made them feel like lesser citizens of the Laboratory and not part of

" $[I ' m]$ like the ugly stepchild of the

family_applied side." the organization's mainstream focus- "like the ugly stepchild of the family."

The effect of this perceived strong emphasis on basic science can be an actual disincentive to engage in translational research. If management measures and rewards researchers' performance according to the number and impact of publications they produce, it is counter to the researchers' interest to spend time moving their discoveries toward use. Sponsors, too, may place heavy stress on basic research. Workshop participants reported instances of projects losing funding due to collaborations with industrial partners. 


\section{Organizing to foster translation}

Much discussion at the workshop addressed organizational changes that could encourage the progression of science toward use. Most of these potential changes concerned internal ORNL structure, but a few called for using the Laboratory's influence to interact more effectively with its sponsors, partners, collaborators, and broader society.

2a. Clusters - A concept that gained widespread interest among the participants was the creation of "clusters." Participants referred to clusters as areas that support some specific type of development, such as Silicon Valley, and to a lesser degree the forces that lead regions to develop economic specialties as a development strategy. ORNL-specific discussions depicted clusters as possibly bringing basic scientists, applied researchers, and technology developers together. One participant noted that it has been shown that innovation occurs primarily when these different orientations interact. Examples of such clusters at ORNL were discussed: one that came about as a result of a large funding opportunity, another that was deliberately created through a hiring strategy, and several that resulted from organizational changes.

The importance of communication with industrial users was echoed by other participants, particularly listening when technology developers describe their needs. At least two participants opined that the Laboratory's appropriate role in such cases was to engage in research that industry needs but will not perform itself.

Participants referred to two elements that seem to be key to creating successful clusters: adequate funding and time. Participants noted that one program had several years of good funding that provided the ability to hire strategically and achieve a good mix of basic and applied researchers. Another group leader spoke of the need for patience when integrating scientists of different orientations: "It takes time but the barriers go away."

2b. Ecosystems - In a concept similar in ways to clusters, participants talked about the creation of "ecosystems" that support the translation of science toward use. Model ecosystems, such as those that exist in the Boston-Cambridge area, the Research Triangle, and Silicon Valley, develop where there is a critical mass of basic research (universities or a national laboratory), high-tech industry, and a skilled workforce. These ecosystems are especially effective at translating science toward use not only because they bring basic scientists, applied researchers, and industrial developers into contact with each other, but also because they allow people to move from one of these roles to another and back again.

Participants discussed how ORNL might promote the creation of a similar ecosystem in its region through connections with universities and, especially, with industry. One participant noted that there is a vital medical imaging industry in East Tennessee that relies on isotopes, a strong point of ORNL. This commonality, along with the advanced imaging capabilities of the SNS, could be explored as the initial nucleus of a regional ecosystem. 
Discussions of ecosystems involving ORNL prompted one participant to note that ours is something of an "island ecosystem" due to the lack of a large number of diverse, high-tech industries in the vicinity. The possibility of pursuing a "virtual ecosystem" was also explored. While this approach was thought to have promise, the ability for an individual to exchange roles between the Laboratory and industry-a key advantage of the model ecosystems — would be curtailed since such moves would likely require geographic relocation.

The potential of creating more effective translational ecosystems within the Laboratory was also explored. Participants talked about the need for better flow of information, people, and resources across basic science and applied research divisions. One participant noted that an ecosystem requires nutrients, arguing for better-defined roles and communications to promote translation.

2c. Part-time entrepreneurial leave-To foster better exchange between the Laboratory and industry, workshop participants strongly endorsed the concept of part-time entrepreneurial leave. Currently, a researcher who wants to pursue development of an idea or technology must do so outside the context of employment at ORNL. In addition to the risks normally associated with developing a new product, these researchers also risk losing their connection to the Laboratory and the body of

"There's a lot of reasons that [my career] happened the way it did. It cannot happen today in today's environment." work they have developed. There was consensus among the participants that part-time entrepreneurial leave would minimize these risks and, thereby, remove a significant barrier in translation at ORNL.

One participant spoke of his experience with part-time entrepreneurial leave as one key to his success in translating science toward use. He noted the benefit to ORNL of bringing new ideas to his research group from his day-to-day experiences with industry. That individual did not think he would be able to pursue this approach under current Laboratory rules.

2d. Non-DOE sponsors-Several participants noted the importance of Work-for-Others (WFO) sponsors to translational research at ORNL. They discussed how sponsors typically come to the Laboratory with a specific issue that needs to be resolved. By addressing these issues, the Laboratory helps DOE demonstrate a visible, positive impact on society, and the experience often feeds back to enrich the basic research funded by the department.

In working for non-DOE sponsors, participants emphasized the need to reach out to engage those sponsors and identify their needs. One vehicle for doing so is attending and presenting at conferences that attract potential sponsors. In some cases, as one participant said, at ORNL we "have solutions that are looking for problems." A point made repeatedly was that successful translation depends on understanding the potential sponsor, the end users, and the markets.

While the benefits of performing applied research for WFO sponsors were widely supported among attendees, drawbacks were also identified. In some cases, sponsors may have unrealistic expectations. One participant recalled the aftermath of the 2001 anthrax attacks when sponsors wanted to develop within two years detectors that could recognize toxic bacteria within 10 minutes. A decade later, the technology 
still has not been developed. Another participant noted that the Department of Defense often wants to be able to put a product in the hands of front-line soldiers within 18 months to 2 years. This timeframe often does not allow for needed basic research and application development. A third participant referred to the different pace at which the Laboratory functions relative to industry: "We are not DOE-slow, but industry-slow. When they expect us to have an answer, we don't." Finally, one participant commented that some organizations will promise unrealistic results to get their foot into the door.

\section{Incentives}

"There is no incentive for our

PIs to [innovate], they publish,

they write papers, that's how

they get their money. If you

want them to be innovative,

push it down the line, you

have to make it their interest,

but I don't think that is."
Throughout the course of the workshop, the discussions touched on how the Laboratory's incentive structure promotes publications but not innovation. When management metrics of success focus on publications, especially in high-impact journals, researchers have little time or reason to consider their how their research can be marketed or what types of industries might be interested in their research. Their research is simply "thrown over the fence" with the assumption that someone will eventually find it and pick up.

In all three sessions of the workshop, most participants reiterated that monetary incentives are the strongest incentive for pushing science toward use. A few participants went so far as to clarify that monetary incentives did not mean more funding for research but additional dollars in the researcher's paycheck. In contrast one participant noted that, in his experience "rewards, promotions and accolades in front of their peers are much better for the long run than a check." A combination of financial incentives and recognition may be most effective in driving science toward use. 
APPENDIX D:

SLIDES FROM LUNCHTIME SEMINAR 



\section{APPENDIX D: Slides from Lunchtime Seminar}
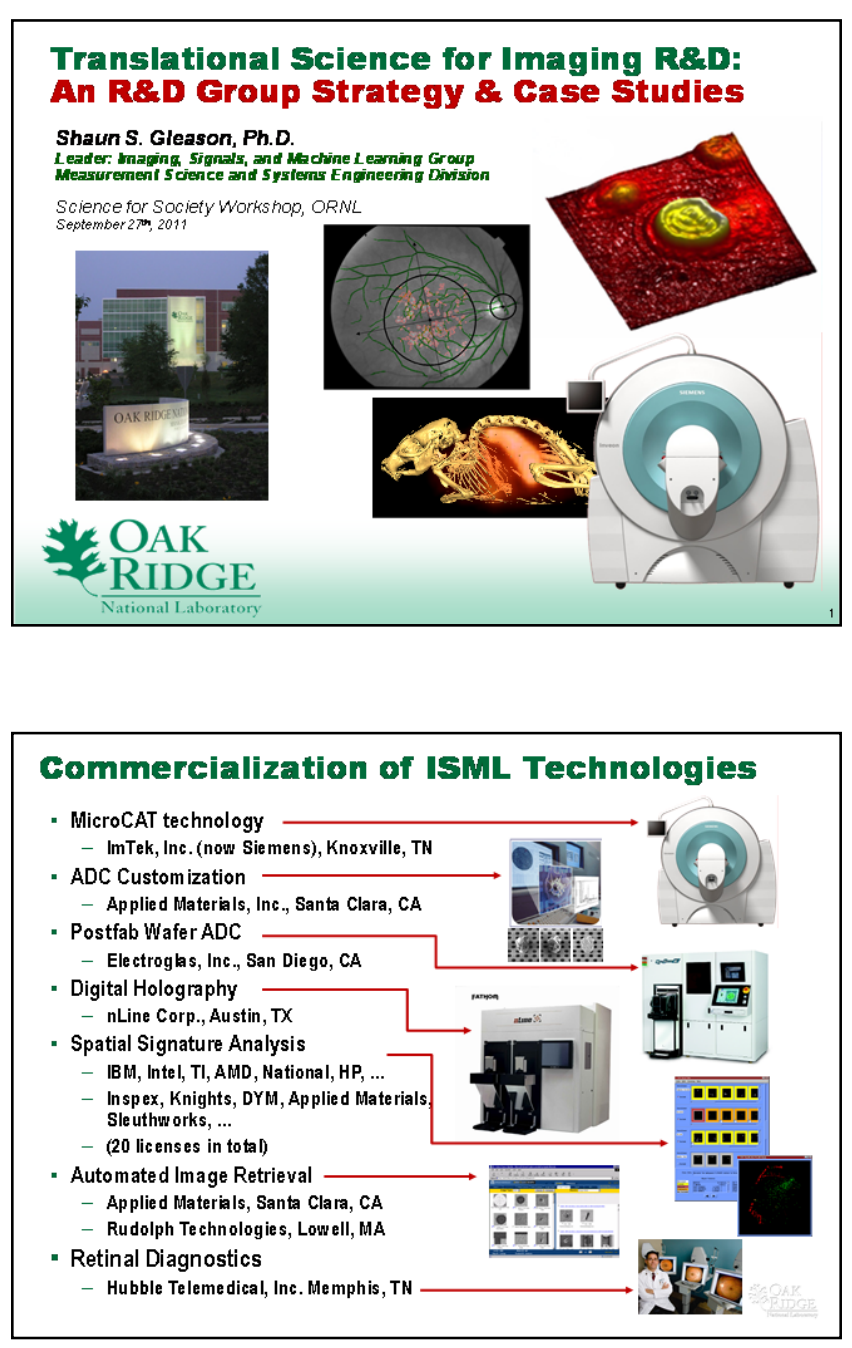

\section{R\&D Group Strategy: Translational Research Doesn't Just Happen...}

\section{- Program Considerations}

- Develop continuum of basic and applied R\&D programs

- DOE: Office of Science (Early Career)

- DOD: DARPA

- DOE: NNSA (NA22)

- Industrial Partnerships (DOE ITP)

- DODIIC (Biometrics)

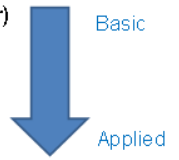

- Attend industry-heavy conferences and workshops

- Interface with customers: Uncover the REAL needs

- Industry funding: Don't shy away from small projects (but don't take on too many!)

$$
\text { SEMATECH MARS NN NaUgaNeEDLES }
$$

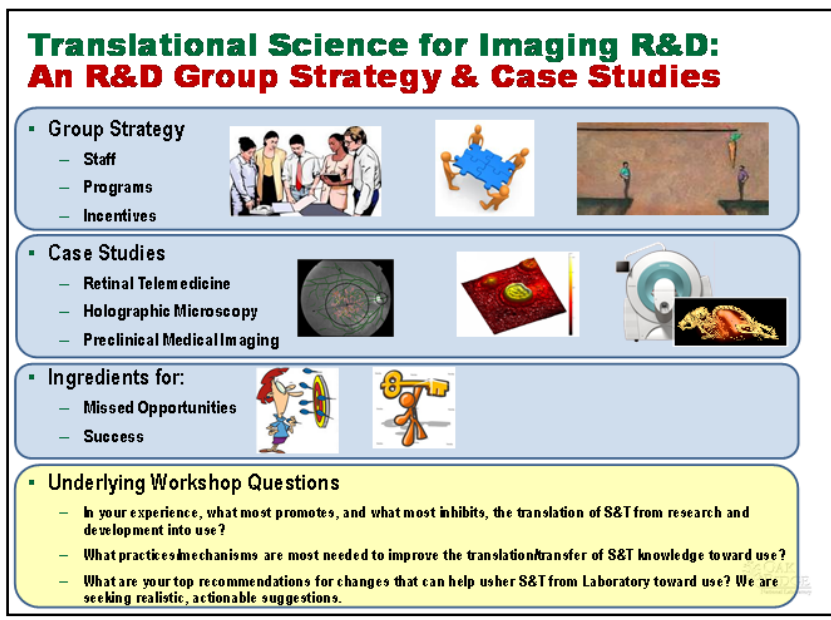

\section{R\&D Group Strategy: Translational Research Doesn't Just Happen...}

\section{- Staff Considerations}

- Create a mix of basic-, applied- and entrepreneurial-minded researchers:

- Hire "entrepreneurial" PIs: They will create success in R\&D and technology transfer

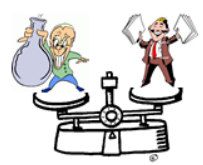

- Strengths common to a talented R\&D PIs and entrepreneurs:

- Marketing: proposals, sponsor reviews and reports are key parts of the laboratory scientists experience.

Sales: boboratory investigators are used to asking for large sums of money with a straight face.

Planning and management: many laboratory scientists function as "independent contractors," hiring collaborators and managing budgets to me et programmatic objectives.

New technology development: this is what we do...

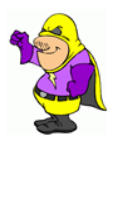

\section{R\&D Group Strategy: Translational}

Research Doesn't Just Happen...

\section{- Incentives}

- Moving technology to real-world use is hard

- Poor perform ance has (sometimes) severe consequences

- Must adapt to never-seen-before scenarios in "the field"

- Engine ering is key com ponent to success

- Staff should be incentivized to:

- Capture IP (dis clo sures, patents, copyrights)

- Pursue applied research challenges

- Include field-te sting for developed te chnology, if appropriate

- Establish industrial partnerships

- Example Rewards

- Acc olades (public recognition, dinners, awards, etc.)

- Financial rewards (raises, IPA, SEA, promotions) 


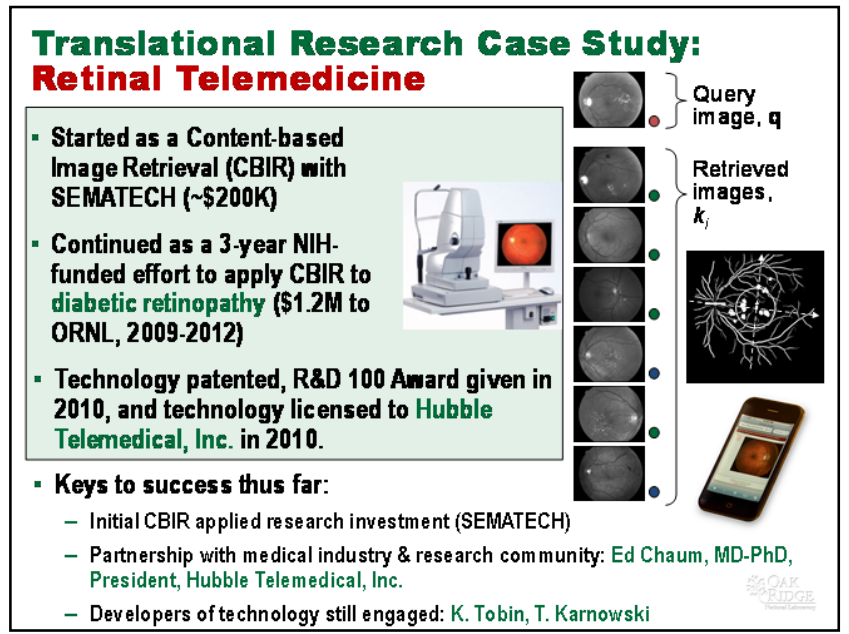

\section{Translational Research Case Study: Preclinical Medical Imaging}

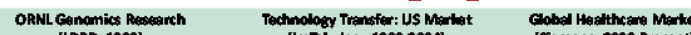
(LRRD, 1998)

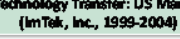
[Siemens, 2008-Prasent]

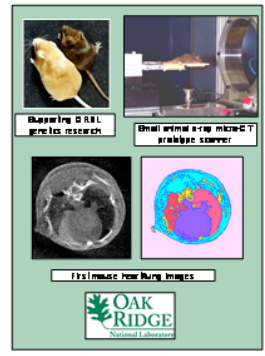
Research prototype,
Groundbreaking scienc
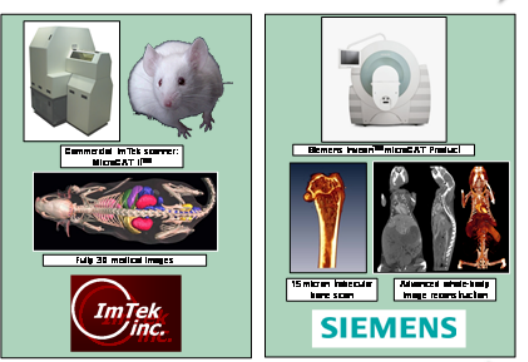
$>50$ Commercial units, $\$ 44$ sales
University Hospitals, Biotech hutstry Worldwide market: $>\$ 30 \mathrm{H}$ sales
Phamaceutical houstry
Translational Research Case Study: Real-time 3D

Digital Holographic Microscopy (DHM) for Biology

- Initially developed 3D DHM for the semiconductor industry (early 2000s)

- Licensed DHM technology (multiple patents) to nLine Systems, Inc. in Austin, TX. Victim of the "dot-com" bubble burst.

- 2 more patents awarded since then : Combined 3D imaging with fluorescence Three-wavelength system for improved signal-to-noise

- Many biological applications have been demonstrated (e.g. real time dynamic cellular imaging.

- Commercialization potential has been high for the last two+ years: $\square$ lynceee tec

- Reasons for delay in translation: Complex technology needs strong engineering support Scientist is risk-averse

No part-time entrepreneurial opportunities

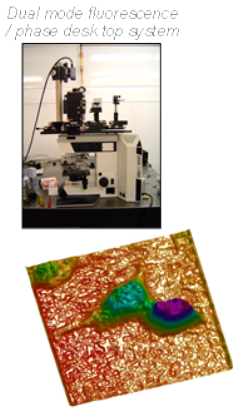

Fibroblast cell division 

\section{Translational Research: Ingredients for...}

- ...miss ed opportunities

- Not planning staff, program s, and incentives for translational research

- Throwing IP over the fence without scientific support

- Fearful m anagem ent (fear of: trouble, extra work, loss of good employees, etc.)

- Legal hurdles

- No safety nets for fledgling entrepreneurial scientists

- ...success

- Constructing a staff, programs, and incentives with an eye toward translational research

- Engaged technology developers throughout translation (basic \& applied R\&D staff

- Supportive management

- Conflict of interest: mitigate, don't e liminate!

rns= Part-time entrep reneurial leave that reduces risk 